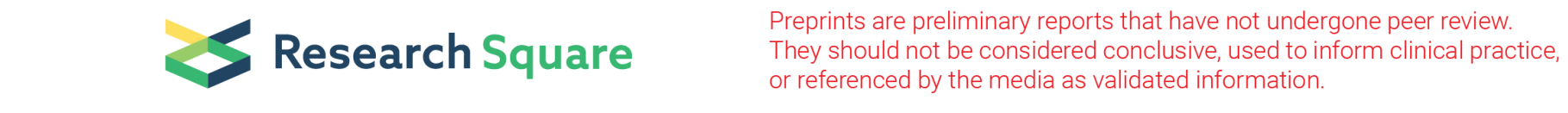

\title{
Parasitic Contamination of Fresh Vegetables in Open Air Markets of Aksum, Ethiopia
}

Gebrehiwot kiros Gebremariam ( $\square$ kirosg2@gmail.com )

Aksum University https://orcid.org/0000-0003-2526-155X

Tsgab Gebrecherkos Girmay

AKU: Aksum University

\section{Research}

Keywords: Parasite, Vegetable, Contamination, risk factor, Market, Aksum

Posted Date: September 8th, 2020

DOl: https://doi.org/10.21203/rs.3.rs-70164/v1

License: () (1) This work is licensed under a Creative Commons Attribution 4.0 International License. Read Full License 


\section{Abstract}

Background: Intestinal parasitic diseases are the foremost causes of illness in humans, responsible for significant morbidity and mortality. Recently, there have been so many reports related to a foodborne illness linked to consuming fresh vegetables, especially in developing countries. The study was aimed to assess the parasitic contamination level of fresh vegetables collected from open air markets in Aksum town, Tigray region, Ethiopia.

Method: A total of 384 samples belonging to six vegetable types were collected randomly from local markets in Aksum town. Samples were washed in saline solution followed by sedimentation for 24 hours.After that the supernatant was decanted leaving the sediment. The sediment was then transferred to a centrifuge tube and centrifuged at 3000 revolution per minute for 5 minutes. Finally, the supernatant was decanted and the sediment was examined under light microscope for protozoan cyst, helminthes ova, and larvae

Results: The overall prevalence of parasitic contamination was $57.3 \%$. The Cabbage was the most frequently contaminated (79.7\%) vegetable succeeded by Spinach (75\%), Lettuce (73.4\%), Potato (46.9\%), Green pepper (37.5\%), and tomato (31.2\%). Among the parasites detected, Taenia spp. proglottides/egg was the most frequent contaminant with $41.1 \%$ prevalence rate followed by Enetrobius vermicularis egg (20.3\%), Hookworm spp.(19.5\%), Fasciola spp. egg (17.2\%), Giardia lamblia cyst (18.5\%), Entamoeba spp. cyst(15.9\%), Strongyloides stercoralis larva (12.5\%),Ascarislumbricoidese gg (9.4\%), and Cryptosporidium spp.Chai-square analysis showed that the type of fertilizer used, educational status of the vendors, status of wash before display, and type of vegetable they produce was statistically and significantly associated with the prevalent parasite forms detected $(P<$ $0.001)$.

Conclusion: This study identified a high prevalence of fresh vegetables contaminated with medically important parasites, thus effective prevention measures such as standard washing before consuming fresh vegetables, and avoiding raw manure as a fertilizer should be implemented to avoid infection from contaminated vegetables.

\section{Background}

Intestinal parasitic diseases are the foremost causes of illness in humans, responsible for significantmorbidity and mortality. It is estimated that 3.5 billion people are affected, and 350 million people are ill as a result of these infections, the majority being children ${ }^{28,29}$. Recently, there have been so many reports related to a foodborne illness linked to consuming fresh fruits and vegetables especially in developing countries ${ }^{30}$. These foodborne diseases which lead to serious health and economic problems are mainly caused by Protozoan and Helminthes parasites ${ }^{1}, 7$. Vegetables are vehicles for the transmission of parasites if contaminated as a result of different associated factors related to planting, collecting, transportation, showcase chain, and improper treatment at domestic ${ }^{3,4}$. Untreated wastewater irrigation, the use of raw manure as fertilizer, improper on-harvest handling and hygienic conditions during preparation are factors that determine the level of contamination ${ }^{2}$.

.Intestinal parasites such as; Ascaris lumbricoides, Cryptosporidium spp., Entamoeba histolytica, Enterobius vermicularis, Fasciola spp., Giardia intestinalis, Hookworm spp., Hymenolepis spp., Taenia spp., Trichuris trichiura, and Toxo cara spp., infect humans who consume contaminated, undercooked, or improperly washed vegetables ${ }^{7}$. Studies also showthat the causes of human parasitic infections are raw or not hygienically prepared vegetables such as; cabbage (Brassica deracea), lettuce (Lactuca sativa), okra, garden egg (Sdanum macropium), cucumber, carrot (Daurus carota), waterleaf (Talinum trangulare), pumpkin (Telfairia), spinach, and tomatoes (Lycoperisicon esculentum) ${ }^{4}$. Further, some studies were carried out to determine the transmitting role of fresh vegetables such as in Khartum, Sudan ${ }^{21}$, in Benha, Egypt ${ }^{31}$, in Hanoi, Vietnam ${ }^{15}$, in Misurata, Libya ${ }^{22}$, in Dahmar city, Yemen ${ }^{23}$, in Iran ${ }^{14}$ and, Jordan ${ }^{24}$. The results in all these studies showed a distinctive level of parasitic contamination of fresh vegetables.

Like other developing countries, Ethiopia is a country with a low sanitation and hygiene, which makes it vulnerable to intestinal parasites. Some studies conducted in Ethiopia similarly reported a high prevalence of parasites from vegetable samples ${ }^{2,9}$, 10,23.Aksum is well known for its old UNESCO-registered architectural heritage, and draws many visitors from around the world. Studies showed that the numbers of tourists who are visiting Aksum are increasing from time to time, and the number of Hotels 
and restaurants is increasing to meet the increasing flow of tourists ${ }^{36}$. It is a fact that fresh vegetables are a common diet in Ethiopia particularly in Aksum during the fasting period. It is also the commonly prepared food item in hotels and restaurants. Hence, the rate of intestinal parasitic infection from the utilization of contaminated vegetables may increase particularly in case the vegetables are inappropriately washed. Thus monitoring and evaluating on the level of parasitic contamination is important to control intestinal parasitic infection in the area. However to our knowledge there is no published data on the status of parasitic contamination of vegetables in and around Aksum. Therefore, this study was conducted to assess the parasitic contamination status of vegetables and associated risk factors in Aksum town, Ethiopia.

\section{Materials And Methods Study area and period.}

The study was carried out in Aksum town, in northern Ethiopia approximately $1010 \mathrm{~km}$ from Addis Ababa, Ethiopia's capital. In the town, the majority of populations (88.3\%) are Orthodox Christian followers ${ }^{35}$. Since the area in and around Aksum town is suitable to grow fruits and vegetables many farmers are engage in producing a variety of vegetables. The vegetables are supplied from the surrounding villages directly by the farmers. Customers purchase the vegetables either from the farmers or retailers. This study was conducted from March 1 to March 23, 2019, which is the fasting period for the Orthodox Christian followers living in the town.

\section{Sample collection and parasitological Examination}

To conduct the study a random sample of 384, 64 from 6 distinct vegetable types namely; Lettuce (Lactuca sativa), Cabbage (Brassica Oleracea), Spinach (Spinacia oleracea), Pepper (Capsicum annum), Potato (Solanumtuberosum) and Tomato (Lycopersicon esculentum) was purchased from the multiple vendors in Aksum markets. Just one vegetable from a single vendor was collected. Each vegetable sample was placed in an isolated plastic sack and labeled with a code and date of collection. Samples were transported to the Biology laboratory of Aksum University for parasitological analysis. The samples were prepared for examination within three hours of collection time.Each vegetable sample was cuted into pieces and weighted to 200 grams. The chopped samples were washed separately using 1LNormal saline to detach the parasite stages (Ova, cyst, and larvae) of helminths and protozoa. After overnight sedimentation of the washing solution, $15 \mathrm{ml}$ of the sediment was then transferred to a centrifuge tube using a sieve to remove undesirable matters. To concentrate the parasite stages, the tube was centrifuged at $3000 \mathrm{rpm}$ for five minutes (using Labtech, Model.No.AC 2305 centrifuge). After centrifugation, the top water was decanted carefully leaving about five milliliters of the sediment. The sediment was then agitated gently to redistribute the parasite stages. Finally, Lugol (lodine) stained slides were prepared from each sample sediment and examined under a light microscope for protozoa cyst, helminths ova, and larvae using $\times 10$ and $\times 40$ objectives ${ }^{15,7}$. Besides, Modified ZiehINeelson staining technique was employed to identify Oocysts of Cryptosporidium, Isospora beli and Cyclospora spp. The parasite stages were identified based on morphological details as described by Souls ${ }^{32}$.

To identify the factors associated with vegetable contamination, vendors were asked to answer questions about the possible source of contamination for vegetables including; their level of education, the fertilizer type used, and the status of the wash of the vegetables before display and the type of vegetable they produced to identify the factors related to the prevalence of parasites.

\section{Data analysis}

The data were analyzed through descriptive prevalence and count statistics. The onesample proportion test was also used to assess the significance of vegetable contamination prevalence. To identify the factors related to the prevalence of parasites in vegetables, a Chai-square analysis was used. This is achieved using the statistical software of SPSS version 20 and $95 \%$ confidence.

\section{Result}


From a total of 384 samples screened for parasites,220(57.3\%) had at least one and at most seven parasites detected (Table 1). Out of 384,71 vegetable samples were contaminated by only one parasite and 52 vegetable samples were contaminated by two parasites. However, there were only six vegetable samples with seven parasite contamination. The highest prevalence of parasites was detected in cabbage (Brassica oleracea) $(79.7 \%)$ succeeded by spinach (Spinacia oleracea) $(75 \%)$, and lettuce (Lactuca sativa) (73.4\%). Tomato (Solanum tuberosum) with $31.2 \%$ prevalence is the least contaminated vegetable. The onesample proportion test on the contaminated vegetables indicated that the prevalence is statistically significant with all Pvalues less than $5 \%$.

As shown in Table 2, the average prevalence of parasites contamination in the variety of vegetable samples was $57.3 \%$. Nine different kinds of parasite forms were detected from the vegetables examined. Its prevalence, however, showed a considerable variation. Particularly, the most frequently observed was Taenia spp. proglottides/egg (41.1\%) followed by Enetrobius vermicularis egg (20.3\%) and Hookworm spp. egg (19.5\%). Besides, Fasciola Spp.egg, Giardia lamblia cyst, and Entamoeba spp.cyst showed considerable decrement namely, $17.2 \%, 18.5 \%$, and $15.9 \%$ respectively. However, Strongyloides stercoralis larva, and Ascaris lumbricoides egg was the least frequently detected parasitic forms with $12.5 \%$ and $9.1 \%$ prevalence rates, respectively.

The distribution of the parasites on fresh vegetables (Table 2) also showed that Taenia spp. was the most prevalent of all parasites in all vegetable samples with a prevalence rate of $60.9 \%$ in Spinach, 56.2 in Cabbage, $45.3 \%$ in Lettuce, $37.5 \%$ in Potato, $26.6 \%$ in Green pepper, and $20.3 \%$ in Tomato.Next to Taenia saginata the second frequently detected parasite in Lettuce was, Hookworm spp. (31.25\%) followed by G.lamblia(29.7\%).

In Cabbage, G. lamblia, and Hookworm spp. egg/larvae were detected as second and third most prevalent parasites with $26.6 \%$ and $25 \%$ prevalence rate respectively. In spinach E. vermicularis egg and Fasciola spp.was the second (28.1\%) and third frequently detected parasites. On the other hand, G. lamblia cyst was the second prevalent parasite (17.2\%) in Green pepper samples succeeded by E. vermicularis, Hook worm spp.which was observed in $12.5 \%$ each.

In tomato samples $G$.lambilia cyst and Cryptosporidium spp.Oocyst.were recorded as the second most prevalent parasite stagess with a $10.9 \%$ prevalence each followed by E. histolytica, Hook worm spp., and E.vermicularis which were detected $6 \%$ each. The onesample proportion test result showed that all of the parasite detection proportions were found to be statistically significant with Pvalues less than 5\% (Table 2).

The chaisquare analysis showed that the type of fertilizers used, the educational status of the vendors, the type of vegetable they produce, and the status of wash before display was found statistically and significantly associated with the prevalent parasite contamination $(\mathrm{P}<0.001)$ (Table 3$)$.

Table 1

Prevalence rate of parasitic contamination in fresh vegetables collected from local markets in Aksum town from March 1 to March 23, 2018.

\begin{tabular}{|c|c|c|c|c|c|c|c|c|c|c|}
\hline \multirow[t]{2}{*}{$\begin{array}{l}\text { Type of } \\
\text { vegetable }\end{array}$} & \multirow{2}{*}{$\begin{array}{l}\text { No. of } \\
\text { samples } \\
\text { examined }\end{array}$} & \multirow{2}{*}{$\begin{array}{l}\text { No.of } \\
\text { positive } \\
\text { (\%) }\end{array}$} & \multirow[t]{2}{*}{$\begin{array}{l}\mathrm{p}- \\
\text { value }\end{array}$} & \multicolumn{7}{|c|}{$\begin{array}{l}\text { The number of parasite species detected from the samples with the } \\
\text { percent in brackets. }\end{array}$} \\
\hline & & & & One & Two & Three & Four & Five & Six & Seven \\
\hline Lettuce & 64 & 47(73.4) & & 11(17.2) & 11(17.2) & $8(12.5)$ & $5(7.8)$ & $3(4.7)$ & $6(9.4)$ & $3(4.7)$ \\
\hline Cabbage & 64 & $51(79.7)$ & & 19(29.7) & 13(20.3) & $2(3.1)$ & $6(9.4)$ & $3(4.7)$ & $8(12.5)$ & 0 \\
\hline Spinach & 64 & $48(75)$ & & 19(29.7) & $9(14.1)$ & $3(4.7)$ & $7(10.9)$ & $8(12.5)$ & $1(1.6)$ & $1(1.6)$ \\
\hline $\begin{array}{l}\text { Green } \\
\text { pepper }\end{array}$ & 64 & $24(37.5)$ & $0.00 *$ & $8(12.5)$ & $7(10.9)$ & $1(1.6)$ & $3(4.7)$ & $4(6.2)$ & 0 & $1(1.6)$ \\
\hline Potato & 64 & $30(46.9)$ & & $7(10.9)$ & $8(12.5)$ & $5(7.8)$ & $6(9.4)$ & $2(3.1)$ & $2(3.1)$ & 0 \\
\hline Tomato & 64 & $20(31.2)$ & & $7(10.9)$ & $4(6.2)$ & $3(4.7)$ & $1(1.6)$ & $1(1.6)$ & $3(4.7)$ & $1(1.6)$ \\
\hline Total & 384 & $220(57.3)$ & & 71(18.5) & $52(13.5)$ & 22(5.7) & $28(7.3)$ & $21(5.5)$ & $20(5.2)$ & $6(1.6)$ \\
\hline
\end{tabular}


*Indicates the prevalence of the contamination is statistically significant.

Table 2

Distribution of Intestinal parasites contamination in fresh vegetables collected from local markets in Aksum town from March 1 to March 23, 2018.

\begin{tabular}{|c|c|c|c|c|c|c|c|c|}
\hline \multirow[t]{2}{*}{ Detected parasites } & $\begin{array}{l}\text { Lettuce } \\
(n=64)\end{array}$ & $\begin{array}{l}\text { Cabbage } \\
(n=64)\end{array}$ & $\begin{array}{l}\text { Spinach } \\
(n=64)\end{array}$ & $\begin{array}{l}\text { Green pepper } \\
(n=64)\end{array}$ & $\begin{array}{l}\text { Potato } \\
(n=64)\end{array}$ & $\begin{array}{l}\text { Tomato } \\
(n=64)\end{array}$ & $\begin{array}{l}\text { Total } \\
(\mathrm{N}=384)\end{array}$ & P-value \\
\hline & $\#(\%)$ & $\#(\%)$ & $\#(\%)$ & $\#(\%)$ & $\#(\%)$ & \#(\%) & $\#(\%)$ & \\
\hline \multirow{2}{*}{$\begin{array}{l}\text { E. histolytica/ dispar } \\
\text { G.lamblia }\end{array}$} & $16(25)$ & 13(20.3) & $14(21.9)$ & $4(6.2)$ & $8(12.5)$ & $6(9.4)$ & 61(15.9) & \\
\hline & 19(29.7) & $17(26.6)$ & $9(14.1)$ & 11(17.2) & $8(12.5)$ & $7(10.9)$ & $71(18.5)$ & \\
\hline \multirow{2}{*}{$\begin{array}{l}\text { Cryptosporidium Spp. } \\
\text { Ascaris/umbricoides }\end{array}$} & 12(18.8) & $4(6.2)$ & $5(7.8)$ & $0(0.00)$ & $0(0.00)$ & 7(10.9) & $28(7.3)$ & \\
\hline & $9(14.1)$ & 12(18.8) & $4(6.2)$ & $2(3.1)$ & $5(7.8)$ & $3(4.7)$ & $35(9.1)$ & \\
\hline \multirow{2}{*}{$\begin{array}{l}\text { Strongylodes stercoralis } \\
\text { Taenia spp. }\end{array}$} & $15(23.4)$ & $10(15.6)$ & $8(12.5)$ & $6(9.4)$ & $4(6.2)$ & $5(7.8)$ & $48(12.5)$ & $0.000 *$ \\
\hline & $29(45.3)$ & $36(56.2)$ & $39(60.9)$ & 17(26.6) & $24(37.5)$ & $13(20.3)$ & 158(41.1) & \\
\hline \multirow{3}{*}{$\begin{array}{l}\text { Hook worm spp. } \\
\text { Enterobius vermicularis } \\
\text { Fasciola spp. }\end{array}$} & $20(31.2)$ & $16(25)$ & $14(21.9)$ & $8(12.5)$ & 11(17.2) & $6(9.4)$ & 75(19.5) & \\
\hline & $17(26.6)$ & $15(23.4)$ & $18(28.1)$ & $8(12.5)$ & $14(21.9)$ & $6(9.4)$ & 78(20.3) & \\
\hline & $12(18.8)$ & $15(23.4)$ & $16(25)$ & $8(12.5)$ & $10(15.6)$ & $5(7.8)$ & $66(17.2)$ & \\
\hline
\end{tabular}

*Indicates the prevalence of the parasite is statistically significant. 
Table 3

Chai-square analysis of the factors associated with the prevalence of Intestinal parasites in fresh vegetable samples collected from local markets in Aksum town from March 1 to March 23, 2018.

\begin{tabular}{|c|c|c|c|c|}
\hline \multirow[t]{2}{*}{ Variables } & \multicolumn{4}{|c|}{ Chai-square analysis } \\
\hline & Number [\%] & Total & $x^{2}$ & P-value \\
\hline Vegetable type & & & 58.962 & $0.00 *$ \\
\hline Lettuce & $47(73.4)$ & 64 & & \\
\hline Cabbage & $51(79.7)$ & 64 & & \\
\hline Spinach & $48(75)$ & 64 & & \\
\hline Green pepper & $24(37.5)$ & 64 & & \\
\hline Potato & $30(46.9)$ & 64 & & \\
\hline Tomato & $20(31.2)$ & 64 & & \\
\hline Total & $220(57.3)$ & 384 & & \\
\hline Educational status & & & 170.113 & $0.00 *$ \\
\hline No education & 188(85.5) & 220 & & \\
\hline Grade 1-8 & $19(27.5)$ & 69 & & \\
\hline Above 8 & 13(13.7) & 95 & & \\
\hline Total & $220(57.3 \%)$ & 384 & & \\
\hline Type of fertilizer used & & & 100.711 & $0.00 *$ \\
\hline No fertilizer & $39(66.1)$ & 59 & & \\
\hline Animal manure & 163(74.8) & 218 & & \\
\hline Synthetic fertilizer & $18(16.8)$ & 107 & & \\
\hline Total & $220(57.3)$ & 384 & & \\
\hline Status of wash before display & & & 129.500 & $0.00 *$ \\
\hline Washed & 201(77) & 261 & & \\
\hline Unwashed & $19(15.4)$ & 123 & & \\
\hline total & $220(57.3)$ & 384 & & \\
\hline
\end{tabular}

*Indicates theassociation between the factors and parasite contamination is statistically significant

\section{Discussion}

The study showed that the vegetables were contaminated by cyst, egg, and larvae of intestinal parasites. The total positive findings for parsite stages were 220(57.3\%) samples in this study. The detected parasite stages are; Taenia spp. proglottides/egg, Hookworm egg and larvae, Entamoeba spp. cyst, Enterobius vermicularis egg, Ascaris lumbricoides egg, Fasciola spp. egg, Strongyloides stercoralis larvae, and Giardia lamblia cyst. Of these, the most detected parasitic form was Taenia spp. proglottides/egg (41.1\%), and the least detected was cryptosporidium spp. (7.3\%).

The average prevalence is higher compared to some studies reported in Ethiopia 9 , 10, where they reported, $54.4 \%$ and $32.41 \%$ prevalence rate respectively but lowers than ${ }^{2}$ which reported $57.8 \%$. Moreover, compared to the study from Sudan ${ }^{20}$, Libya ${ }^{21}$, Iran ${ }^{13}$, and Jordan ${ }^{23}$, the prevalence rate is highest. But it is lower than the comparable study reported from Ghana ${ }^{16}$, Nigeria $^{23}$, Kenya ${ }^{33}$ and Iran ${ }^{33}$ that showed prevalence rates of $57.5 \%, 76 \%, 75.9 \%, 79 \%$, and Dahmar city, Yemen's highest rates (100\%) ${ }^{26}$. 
The geographic position and type and number of samples examined, detection methods, different techniques employed in the laboratory, water types used for irrigation, post-harvesting methods and the type of water used for the wash of vegetables may be attributed to this variation $8,21,20$.

Cabbage (79.7\%), followed by spinach (75\%) and lettuce (73.4\%) were among the most commonly contaminated vegetables of the vegetables examined(Table 1). This difference in contamination rates between the vegetables could be due to shape and sizedifferences ${ }^{34}$. In particular, Cabbage and Spinach have larger and uneven surfaces which make the parasites attach more easily to the surface. This study is consistent with ${ }^{15}$ reports that leafy vegetables are contaminated highly in Hanoi, Vietnam in comparison to root and fruit vegetables. Beside, Spinach's rough surface and leaf fold can retain dirt which cannot be removed easily 15 .

The smooth surface of green pepper and tomato, by contrast, can reduce the parasite attachment rate ${ }^{34}$ that the lower contaminating rate is supported in this study. The relatively low potato contamination in this study can be attributable to the tuber growth under the ground that minimizes contamination.

Different parasites have been detected in this study, the most prevalent of which are Taenia saginata proglottide/Egg (41.1\%) (Tabe2). The results correspond to studies in Mekelle district, Ethiopia ${ }^{1}$, and the district of Malayer, $\operatorname{Iran}^{13}{ }^{3}$, which showed a prevalence rates of $18.8 \%$ and $20 \%$ respectively. In Amman, Jordan (6\%), and Dahamar, Yemen (6.7\%), respectively, the low prevalence rate was reported. Enterobius vermicularis egg (21.3\%) was the second most prevalent parasite stage (Table 2$)$. In Addis Ababa ${ }^{25}$ and Arbaminch ${ }^{27}$, Ethiopia, similar findings were observed ${ }^{10,2,12}$. However, in other areas of Ethiopia and several other countries, it was not detected in vegetable samples ${ }^{10,2,12}$. Differences in hygienic conditions and techniques for the diagnosis of the parasite stages may be attributed to variations in the different studies.

The succeeding prevalent parasite was Hookworm spp. with 19.5\% prevalence rate (Table 2). On the contrary, no hookworm ova were detected in similar studies done on vegetables in Ethiopia $2,10,12$. However, it was reported as a prevalent parasite in studies conducted in Sudan ${ }^{21}$ and Nigeria ${ }^{26}$. This variation may be due to differences in geographical locations, climatic conditions, and types of soil ${ }^{7}$. Giardia lambliawas detected as fourth prevalent (18.5\%) with the highest frequency detected in Lettuce (29.7\%) (Table 2). Similarly, G. lambliawas reported as the most contaminant of Lettuce in Benha, Egypt (15\%) ${ }^{34}$. Fasciola spp. was the fifth detected parasite with a prevalence rate of $17.2 \%$ (Table 2). Lower prevalence rate was reported in Kermanshah, Western Iran $(3.1 \%)^{19}$, Baqa'a, Jordan (4\%0) $)^{24}$ and Yemen (2.8\%) ${ }^{23}$. Entamoeba spp. was detected as sixth frequently occurred parasites (15.9\%) (Table 2). A similar result was reported in Ondo state, Nigeria (20\%) ${ }^{26}$, and Arbaminch, Ethiopia (14.4\%). Higher prevalence was reported in Khartum state, Sudan (42.9\%) ${ }^{21}$, and Low prevalence was reported in Jimma, Ethiopia (5.3\%) ${ }^{2}$.

Strongyloides stercoralis larvae were the seventh detected parasite with a prevalence rate of $12.5 \%$ (Table 2). The finding of this study is similar to the previous report from Jimma, Ethiopia (21.9\% $)^{2}$. The low prevalence rate was reported in Awash, Ethiopia $(6.2 \%)^{10}$, and Kogi state, Nigeria $(6.06 \%)^{3}$. The Highest prevalence rate was reported in two markets in Ghana $(36.4 \%)^{16}$. Ascaris lumbricoides egg was identified as the eighth detected parasite stage (9.1\%)contaminating fresh vegetables in this study (Table 2).A similar result was reported in Katsina state, Nigeria (10.19\%) ${ }^{18}$ and Jimma, Ethiopia (6.7\%) ${ }^{2}$. Highest contamination rate was reported in Awash valley (22.22\%) ${ }^{10}$, and Arbaminch (20.83\%) [7] areas of Ethiopia. In the Khartum state, Sudan, the contamination rate was $2.9 \%{ }^{21}$.Cryptosporidium spp. Oocyst was the least detected parasite stage (7.3\%) in this study. A similar result was reported in Bahridar ${ }^{35}$, Ethiopia who reported a prevalence rate of $4.9 \%$.

The presen study showed that the type of fertilizer used,the status of wash before display, the typeof vegetable they produce, and the educational status of the vendors was statistically and significantly associated with the contamination level of the vegetables $(\mathrm{P}<0.001)$ (Table 3). This finding is consistent with previous reports by ${ }^{9,24}$ who revealed a high prevalence rate of parasites detected from raw manure fertilized vegetables in Mekelle city, Ethiopia, and Amman, Jordan respectively. This result is also in agreement with ${ }^{34}$ who showed the high prevalence of vegetables contamination in Tercha town, southern Ethiopia was associated with the type of vegetables they produce, status of wash, and education status of vendors. In this study, the high prevalence of contamination was detected in washed vegetables than unwashed ones. This result is contrary to ${ }^{7}$ who reported a 
high prevalence rate of parasites detected from vegetable samples unwashed before display in Arbaminch, Ethiopia. The high prevalence of washed vegetables in the present study may be due to the use of wastewater to wash the vegetables.

\section{Conclusion}

The highest levels of fresh vegetables contaminated with intestinal parasite stages were identified. The most frequently detected parasite forms were, in particular, Taeniasaginataproglottides /eggs and Enterobiusvermiculariseggs. The Cabbage was among the most contaminated vegetables screened for parasites. The high incidence of parasite contamination was statistically and significantly related to the type of fertilizer used; status of wash before display, vendor education status and vegetable variety they produce. In terms of transmission of the intestinal parasites to men, contaminated fresh vegetables can play an important role in Aksum markets. Therefore it is highly recommended, for instance, to avoid the use of raw manure as fertilizer, and standard washing before using raw vegetables, to reduce the risk of intestinal parasitic infections from contaminated vegetables.

\section{Declarations}

\section{Ethics approval}

Ethical clearance was obtained from Aksum Universi thical review board.The purpose of the study was explained to the vendors of vegetables prior to data collection, and verbal consent was obtained from every study participant.

\section{Consent for Publication}

All authors have read and approved the final paper

\section{Data availability}

All data generated and analyzed during this study are included in this published article.

\section{Competing Interest}

The authors declare that there is no competing interest regarding the publication of this paper.

\section{Funding}

This study was done by the grant gotten from CNCS/RCSO of Aksum University[AKUR00034/2018], Ethiopia for data gathering only.

\section{References}

1. Yusof AM, Mohammad M,Abdulahi AM, Mohamed Z, Zakaria R, Abdulwahab R. Occurrence of intestinal parasitic contaminations in selected consumed local raw vegetables and fruits in Kuantan, Pahang. Tropical Life sciences Research. 2017; 28: 23-32.doi.21315/tlsr2017.28.1.2

2. Tamirat T, Abdissa B, Zeleke M, Teferi E. Parasitic Contamination of Fruits and Vegetables Collected from Selected Local Markets of Jimma Town, Southwest Ethiopia.International Scholarly Research Notices. 2014; Article ID 382715/ 7 pages.10.1155/2014/382715

3. Omowaye OS, Audu PA. Parasites contamination and distribution on fruits and vegetables inKogi, Nigeria.CIB Tech Journal of Bio-Protocols.2012; 1: 44-47. 
4. Idahosa OT. Parasitic contamination of fresh vegetables sold in Jos Markets. Global Journal of Medical Research. 2011; $11: 20-25$.

5. Haq S, Maqbool A, Khan UJ, Yasmin G, Sultana R. Parasitic Contamination of Vegetables Eaten Raw in Lahore. Pakistan J. Zool. 2014;46:1303-1309.

6. Ebrahimzadeh A,Jamshidi A, Mohammadi S. The Parasitic Contamination of Raw Vegetables Consumed in Zahedan, Iran. Health Scope International Journal. 2013; 1: 205-209. doi.17795/jhealthscope-8209.

7. Fitsum B, Tamirat T, Gelila B, Tsegaye Y. Parasitic contamination of raw vegetables and fruits collected from selected local markets in Arbaminch town, Southern Ethiopia. Infectious Diseases of Poverty. 2017; 6(1):1910.1186/s40249-016-0226-6.

8. Fagbenro MT, Mogaji OH, Oluwole AS, Adeniran AA, Alabi OM, Ekpo UF. Prevalence of Parasites found onVegetables, and Perception of Retailers and Consumers about Contaminationin Abeokuta Area of Ogun State, Nigeria. Clinical Microbiology \& Case Reports.2016;2:1-5.

9. Zewdneh T,Dawit K. Parasitological Contamination of Wastewater Irrigated and Raw Manure Fertilized Vegetables in Mekelle City and Its Suburb, Tigray, Ethiopia. 2012; 4: 77-8.doi.10.4314/mejs.v4i1.74058

10. Girmaye G,Benti G. Parasitic contamination of vegetables irrigated with Awash river in selected farms. Parasitol. Vector Biol. 2014;6:103-109. doi. 10.5897/JPVB2014.0150

11. Federal Democratic Republic of Ethiopia CSA. Population census report of the population and housing census, Ethiopia. 2007.

12. Rahmati K, Fallah M, Maghsood AH, Shamsi-Ehsan T, Matini M. The Prevalence of Parasitic Contamination of Vegetables Consumed in MalayerCity,West of Iran during the year 2014. Avicenna J ClinMicrobiol Infect. 2017; 4(2): 42380.doi:10.5812/ajcmi.42380

13. Uga S, Hoa NTV, Noda S, et al.Parasite egg contamination of vegetables from a suburban market in Hanoi, Vietnam. Nepal MedColl J. 2009;11:75-78.

14. Kudah C, Sovoe S,Baiden F. Parasitic contamination of commonly consumed vegetables in two markets in Ghana. Ghana Med.J.2018; 52: 88-93.doi.10.4314/gmj.v52i2.5

15. Suliman MA, Tamomh AG, Osman TE, et al.Parasitic Contamination of Fresh Vegetables Sold in open Aired Markets in White Nile State, Sudan. Acta Parasitologica Globalis.2018;9: 33-38. doi.10.5829/idosi.apg.2018.33.38

16. Auta T, Bawa JA, Suchet CM. Parasitic Contamination of Common Fresh Fruits and Vegetables Sold in Markets within DutsinMa Town, Katsina State, Nigeria. Journal of Advances in Biology \& Biotechnology. 2017;14:1-8.doi. $10.9734 / J A B B / 2017 / 33010$

17. Salavati Z, Chalehchaleh AA, Rezaei F. Parasitic Infections in Raw Vegetables of Kermanshah, Western Iran and Their Relation with Season and Washing Procedures. Journal of Food Quality and Hazards Control. 2017; 4:37-41.

18. Adenusi AA, Abimbola WA, Adewoga TO. Human intestinalhelminth contamination in pre-washed, fresh vegetables for sale in major markets in Ogun State, Southwest Nigeria. Food Control.2015;50:843-849. doi. 1016/j.foodcont.2014.10.033

19. Mohamed MA,Siddig EE, Elaagip AH, Edris AMM, Nasr AA. Parasitic contamination of fresh vegetables sold at central markets in Khartoum state, Sudan. Ann Clin Microbiol Antimicrob. 2016; 15(no.17):1-7.doi. 10.1186/s12941-016-0133-5

20. Elmajdoub LO, Omar MA, Al-Aboudy MS, AboSheba F, Elzwawi S. Prevalence of parasitic contamination of leafy green vegetables in Misurata, Russian Journalof Parasitology. 2017; 40:1-8.

21. Al-Sanabani A, Algalil FMA, Radman BA, Al-Manusori RT. Prevalence of intestinal parasites in fresh leafy vegetables in some farms at Dhamar city, Yemen. International Journal of Medicine Research. 2016; 1:7-13.

22. Ismail Y. Prevalence of Parasitic Contamination in Salad Vegetables Collected from Supermarkets and Street Vendors in Amman and Baqa'a Jordan. Polish Journal of Microbiology.2016; 65(no.2): 201-207.doi.10.5604/17331331.1204480

23. Mahlet H. Parasitic contamination vegetables in Addis Ababa. Thesiss.2002; Biology Department, Addis Ababa University, Addis Ababa, Ethiopia.

24. Simon-Oke IA, Afolabi OJ, Obasola OP. Parasitic Contamination of Fruits and Vegetables Sold AtAkure Metropolis, Ondo State, Nigeria. Researcher. 2014; 6: 30-35. 
25. ROSA.A preliminary survey of the microbiological and parasitological quality of some locally produced and marketed vegetables done as part of the ROSA research activityin Arbaminch, Ethiopia.2009; pp.43-44

26. Nokes C, Bundy DAP. Does helminth infection affect mental processing and educational achievement?. Today. 1994;10:1418.doi. 10.1016/0169-4758(94)90348-4.

27. WHO. Control of Tropical Diseases. Geneva: World Health Organization; 1998.

28. Abougrai AK, Nahaiksi MH, Madi NS, Saied MM, Ghenkghesh KS.Parasitologicalcontamination in salad vegetables in Tripoli, Libya.Food Control. 2010;21:760-762.doi. 1016/j.foodcont.2009.11.005

29. Soulsby E. Helminths, arthropods and protozoa of domesticated animals.English language book society .London, UK: BaillereTindall Ltd; 1982

30. Yarango RMN, Allo PA, Kabiru EW, Nyanchongi BO. The risk of pathogenic intestinal parasitic infections in Kissi Municipality, Kenya.BMC public health.2008; 14 (no.8); article 237.doi. https://doi.org/10.1186/1471-2458-8-237

31. Ezatpour B, Chegeni AS, Abdollahpour F, Aazami M, Alirezaei M. Prevalence of parasitic contamination of raw vegetables in Khorramabad, Iran. Food control.2013;34(no.1):92-95.

32. Eraky MA, Rashed SM, Nasr ME, El-Hamshary AMS, El-Gahnnam AS.Parasitic contamination of commonly consumed fresh leafy vegetables in Benha,Egypt. Journal of Parasitology research.2014; 2014:1-7. doi.10.1155/2014/613960.

33. Aksum. Demographics. Available at:https://en.wikipedia.org/wiki/Axum\#citenote4, .Accessed on Saturday17/07/2019.

34. Fitsum B, Teha S. Fruit and vegetable contamination with medically important helminths and protozoans in Tarcha town, Dawuro zone, South West Ethiopia. Research and Reports in Tropical Medicine. 2019;10: 19-23.

35. Getaneh A, Mezgebu N, Megbaru A.Parasitic Contamination of Fruits and Vegetables Collected from Local Markets of Bahir Dar City, Northwest Ethiopia. Research and Reports in Tropical Medicine.2020;11:17-25.

36. Gebreanenya G K, Meaza H B. Socio-Economic Impacts of Tourism in Axum Town, Tigray Regional State, Ethiopia. Journal of Tourism and Hospitality Management.2017;5 (no.1): 1-24. doi: 10.17265/2328-2169/2017.02.001

\section{Supplementary Files}

This is a list of supplementary files associated with this preprint. Click to download.

- BMCparasiteandvectoronparasitecontamination.pdf 